\title{
ERS International Congress, Madrid, 2019: highlights from the Allied Respiratory Professionals" Assembly
}

\author{
Ana Oliveira ${ }^{1,2,3,13}$, Matthew Rutter ${ }^{4,13}$, Juan Carlos Quijano-Campos ${ }^{5,13}$, \\ Beatriz Herrero-Cortina ${ }^{6,7,13}$, Marco Clari ${ }^{8,13}$, Aoife O’Rourke ${ }^{9,13}$, \\ Aisling McGowan ${ }^{10}$, Chris Burtin ${ }^{11}$, Andreja Sajnic (1) ${ }^{12}$ and Jana De Brandt ${ }^{11}$
}

Affiliations: ${ }^{1}$ School of Rehabilitation Science, McMaster University, Hamilton, Canada. ${ }^{2}$ West Park Healthcare Centre, Toronto, Canada. ${ }^{3}$ Lab 3R - Respiratory Research and Rehabilitation Laboratory, School of Health Sciences (ESSUA), University of Aveiro, Aveiro, Portugal. ${ }^{4}$ Lung Function Dept, Cambridge University Hospitals, Addenbrookes Hospital, Cambridge, UK. ${ }^{5}$ Research and Development, Royal Papworth Hospital NHS Foundation Trust, Cambridge Biomedical Campus, Cambridge, UK. ${ }^{6}$ Centre for Inflammation Research, Queen's Medical Research Institute, University of Edinburgh, Edinburgh, UK. ${ }^{7}$ Universidad San Jorge, Zaragoza, Spain. ${ }^{8}$ Dept of Public Health and Pediatrics, University of Turin, Turin, Italy. ${ }^{9}$ Respiratory Dept, Cork University Hospital, Cork, Ireland. ${ }^{10}$ Dept of Respiratory and Sleep Diagnostics, Connolly Hospital, Blanchardstown, Ireland. ${ }^{11}$ REVAL - Rehabilitation Research Center, BIOMED - Biomedical Research Institute, Faculty of Rehabilitation Sciences, Hasselt University, Diepenbeek, Belgium. ${ }^{12}$ Dept for Respiratory Diseases Jordanovac, University Hospital Center Rebro, Zagreb, Croatia. ${ }^{13}$ These authors contributed equally.

Correspondence: Jana De Brandt, Campus Diepenbeek, Hasselt University, Agoralaan Building A, 3590 Diepenbeek, Belgium. E-mail: jana.debrandtauhasselt.be

ABSTRACT This article provides an overview of outstanding sessions that were (co)organised by the Allied Respiratory Professionals' Assembly during the European Respiratory Society International Congress 2019 in Madrid, Spain. Session content was mainly targeted at allied respiratory professionals such as respiratory physiologists, respiratory physiotherapists and respiratory nurses, and is summarised in this document. Short take-home messages related to pulmonary function testing highlight the importance of quality control. Furthermore, novel findings regarding the assessment of functional status call attention to bodily factors that can affect functional status. Regarding pulmonary rehabilitation, data were presented about the use of equipment and type of exercise training in COPD and lung cancer. Recent developments in physical activity-related research give insight in enablers of physical activity after hospital admission. The importance of integrated respiratory care was also highlighted, with the occupational therapist, nurse, and nutritional and psychological counsellor playing a pivotal role, which relates directly to research in the field of respiratory nursing that formulates the need for more nursing led-interventions in the future. To conclude, this review provides readers with valuable insight into some of the emerging and future areas affecting clinical practice of allied healthcare professionals.

@ERSpublications

A highlights review of selected presentations from \#ERSCongress 2019 by @ERS_Assembly9 http://bit.ly/2VNFgAj

Cite this article as: Oliveira A, Rutter M, Quijano-Campos JC, et al. ERS International Congress, Madrid, 2019: highlights from the Allied Respiratory Professionals' Assembly. ERJ Open Res 2020; 6: 00034-2020 [https://doi.org/10.1183/23120541.00034-2020]. 


\section{Introduction}

The 2019 European Respiratory Society (ERS) International Congress offered allied respiratory professionals a wide range of appealing sessions, i.e. one postgraduate course, three skills workshop, one professional development workshop, two symposia, and 266 presentations spread over three oral presentation sessions, four poster discussions and nine thematic poster sessions. Early career members of the Allied Respiratory Professionals' Assembly, including respiratory physiologists (A. O’Rourke and M. Rutter), respiratory physiotherapists (B. Herrero-Cortina and A. Oliveira) and respiratory nurses (J.C.Quijano-Campos and $\mathrm{M}$. Clari), were asked to report on the following selected sessions by group chairs of the assembly, which focus on recent practical guidelines regarding testing and recent research advances: a skills workshop on diffusing capacity testing, a thematic poster session on nursing care across the spectrum of respiratory illness, two oral presentation sessions on functional status assessment and on rehabilitation and physical activity in respiratory patients, and two well-attended symposia on quality control of lung function testing and on the added value of allied healthcare professionals (AHPs) in integrated respiratory care. The reports that follow attempt to summarise some of the latest scientific and clinical insights gained from each session, targeting delegates who were present in Madrid as well as those unable to attend in person.

\section{Symposium on "New insights into quality control of lung function testing"}

The symposium started with a heartfelt tribute to Maureen Swanney, who dedicated her working life to furthering the field of respiratory physiology and putting others first. She was instrumental in the scope and accreditation of respiratory physiology departments, and had a passion for the quality and standardisation of lung function tests. Maureen was one of the co-authors of the American Thoracic Society (ATS)/ERS technical standard on spirometry featured in this symposium [1]. Prior to this, she had worked on improving lung function interpretation: encouraging the use of universal lung function reference equations [2-4], and using lower limits of normal instead of percent predicted and fixed thresholds $[5,6]$. She had an appreciation for local quality-assured spirometry and wanted to share this practice with other professionals, setting minimum standards for training and competency requirements [7]. The focus of her $\mathrm{PhD}$ work was the validation of the forced expiratory volume in $6 \mathrm{~s}$ to make lung function more accessible in primary care whilst maintaining quality and safety for patients [8]. She was recognised nationally and internationally, and is an exemplary role model for all women in science, inspiring respiratory physiologists and scientists alike.

Maureen was due to present on quality assurance, which was such a key aspect of her work. The role of quality assurance programmes for respiratory physiology testing is regarded as best practice and was the focus of the first talk entitled "What's new in spirometry biological quality control" by B. Thompson (Australia). A review of primary care practice in Australia [9] revealed a lack of understanding of the simplest quality assurance practices and that equipment manufacturers were not promoting calibration syringes for calibration verification checks. Biological quality control (BioQC) testing is also considered best practice, ensuring the quality of results and allowing identification of issues with the equipment and software $[10,11]$. Data presented showed that the evidence demonstrating the benefits of using BioQC data is minimal. Standards recommend that BioQC subjects be healthy [10]; however, the recommendations do not account for inherent variability such as ageing. Other issues identified were that, in departments with multiple pieces of equipment, the process is time consuming and requires enough staff numbers to perform quality assurance daily or weekly. The recommendations are to replace BioQC with quality control processes using mechanical devices such as calibrated syringes, isothermal lungs, waveform generators and simulators for lung function testing.

Having ensured the equipment is operating accurately, confirming the tests are performed to a high standard is also vital. An update on the ATS/ERS technical standard on spirometry was given by B. Graham (Canada) [1], reflecting changes in technology and best practice for spirometry performance. Six main areas of improvement were identified: patients, equipment, operator, procedure, analysis and quality assessment. These are presented in table 1.

Spirometry is a large part of respiratory diagnostics; however, other tests require the same high standards. A. Kendrick (UK) followed with his talk on "How to remain in line with the new $D_{\mathrm{LCO}} / D_{\mathrm{LNO}}$ guidelines". The diffusing capacity of the lung for carbon monoxide $\left(D_{\mathrm{LCO}}\right)$ and diffusing capacity of the lung for nitric oxide $\left(D_{\mathrm{LNO}}\right)$ guidelines $[11,13]$ have been updated to include both classic and rapid gas analysers (RGAs), the latter improving test quality in both methods. Test gas mixtures have been standardised to include the tracer gas nitric oxide and fractional inspired oxygen set to $21 \%$. The acceptability and repeatability criteria have been revised, introducing a quality control grading system. There are quality assurance process recommendations to ensure accurate measurement. A key aspect of quality assurance is a $D_{\mathrm{LCO}}$ simulator, which identifies instrument failures not recognised by routine quality control and calibration procedures [14]. Regular simulator use leads to improved confidence in result accuracy for patient management benefit. 
TABLE 1 Updated areas of the American Thoracic Society/European Respiratory Society technical standard on spirometry

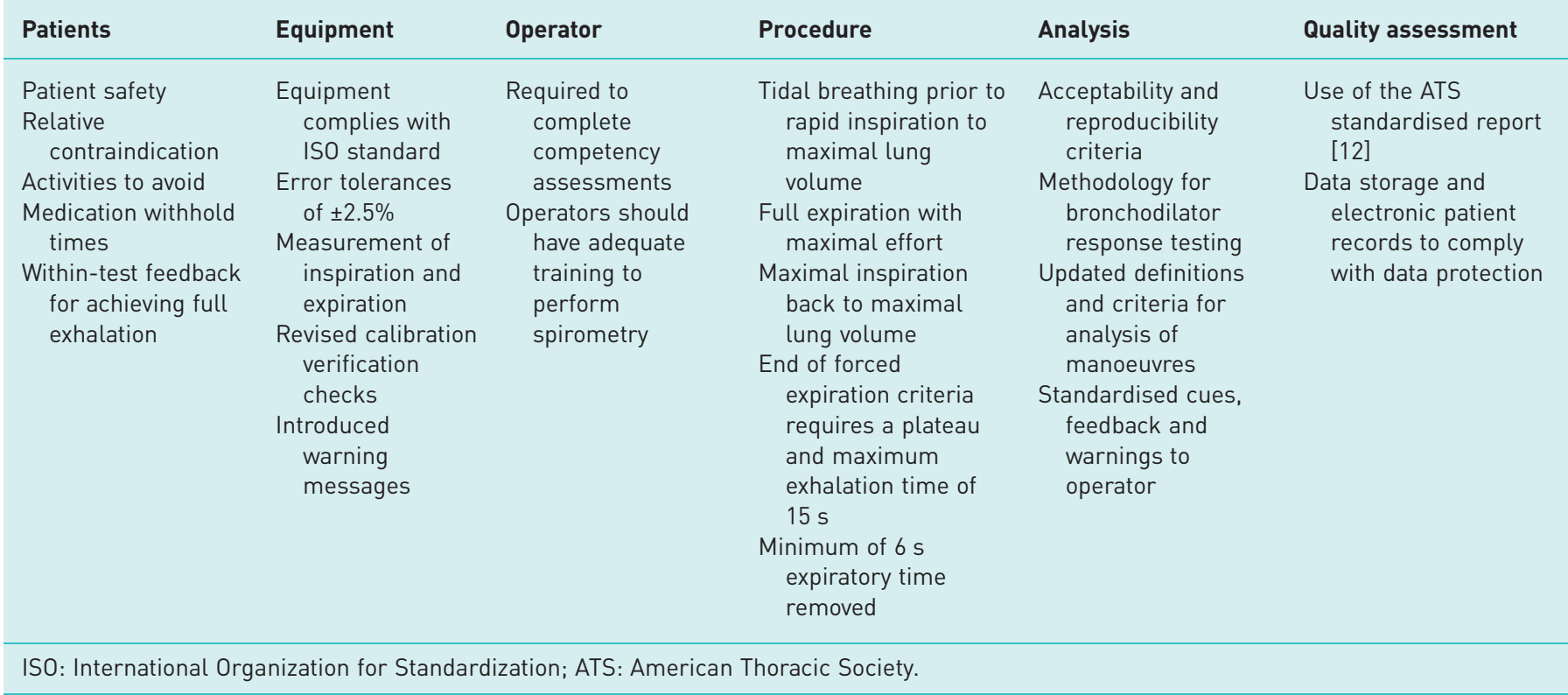

Cardiopulmonary exercise testing (CPET), more so than its less intricate counterparts, requires a stringent quality control process due to the complexity of measurements incorporating ventilation, cardiac and metabolic components. M. Johnson (UK) recognised three areas that impact the quality control of CPET (hardware, subject testing and data processing) in her talk "Cardiopulmonary exercise testing: can you trust the data?". Hardware relies on verification checks of flow sensor and gas analysers. Delay time between sample collection at the mouth and gas analysis is incredibly important; if delay time is incorrectly set, variation between measured and actual results increases with test duration [15]. Systems can be verified using BioQC to indicate equipment precision rather than accuracy, and simulators, although not widely available, provide data on accuracy but not precision. It is important to check equipment such as ergometers or treadmills, calibration syringes, and gas cylinder concentration regularly, as these can introduce errors not routinely identified through calibration. During subject testing, there are multiple sources of error; therefore, it is important to check the data are as expected. Sources of error are the ergometer or treadmill, mask leaks, sample line collection, ECG variability (abnormality or artefact), and blood gas sampling time. The data processing relies on using a standardised method for data averaging and data being presented in the conditions it was measured (e.g. body temperature and pressure, saturated (BTPS)). There are a wide range of reference values available; therefore, selection should represent the population being measured utilising the same measurement method (e.g. ergometer or treadmill).

With all the quality control processes in place, it is important to understand if they are being maintained and if not, what led to the failures. A quality data management (QDM) process introduces precision and accuracy of measurements undertaken, and reduces potential errors, as emphasised by J. Blonshine (USA) in his talk on "Recent advances in data management". QDM improves efficiency and supports the standards required for accreditation. Guidelines recommend regular checks but multiple factors must be considered when designing a QDM; frequency of checks should be relative to the volume of tests performed and the number of devices/staff available. The presented data demonstrated that failures in calibration were often related to performance of checks as opposed to actual equipment faults. The recommended QDM process should start with the simplest checks first and then progress to the most complex, with errors being rectified at each stage of identification. The multilayered approach utilises multiple methods of quality control, and understanding of what is being measured and why they fail. This means that most errors will be preventable.

Take-home messages

In summary, to have a quality-assured diagnostic service, it is necessary:

- To understand the quality control mechanisms and their limitations in the context of patient testing.

- To have up-to-date processes incorporating best practice from current guidelines.

- Introduce a QDM process to monitor quality control and identify/prevent errors. 


\section{Skills workshop on diffusing capacity testing}

Specialists in respiratory physiology delivered two skills workshops focused on the 2017 ERS/ATS standards for diffusing capacity testing of the lung [11]. The aim of these workshops was to better inform current practice through small group education targeting the following four key areas that are discussed below. Table 2 is provided as a summary of the highlights from each of the four workstations.

\section{Calibration, quality control and system settings \\ F. Burgos (Spain) and F. De Jongh (The Netherlands)}

This workstation aimed to demonstrate best practice for RGA, quality control and appropriate system settings to achieve accurate testing according to the 2017 standards. There were four main areas discussed during this workstation presentation: calibration, technical aspects of a RGA, the problem of potential leaks and the influence of ambient conditions on test quality. A clear understanding of these factors and how they impact the quality of results is fundamentally important to safeguard against poor practice and erroneous results. It was advocated to ensure the accuracy of the thermometer and barometer used for checking ambient conditions, in order to optimise quality. Furthermore, we should check the system settings such as dead space, pressure range, volume and BTPS factor, and should ensure that calibration for volume and pressure is accurate by checking whether the calibration syringe is within range, with proof of date of calibration and volume accuracy at different flow rates. Record keeping of trouble shooting, any system problems, and tracking of service and maintenance should be maintained. When upgrading software and equipment one needs to confirm that the $D_{\mathrm{LCO}}$ is correct using quality control measures. Regular gas checks using a calibration syringe or $D_{\mathrm{LCO}}$ simulator was also recommended.

\section{Technical aspects of diffusing capacity testing}

\section{A. Kendrick (UK) and B. Cooper (UK)}

KROGH [16] developed the first method to measure the single-breath uptake of carbon monoxide in 1915. Her research was designed to show that passive diffusion could explain oxygen transfer from the alveolar gas to the pulmonary capillary blood. Additionally, this approach sets the grounds for the current

\section{TABLE 2 Synopsis of the diffusing capacity of the lung for carbon monoxide $\left(D_{L C O}\right)$ skills workshop}

\begin{tabular}{|c|c|c|c|}
\hline Calibration, QC and settings & Technical aspects & Standardisation of test performance & $\begin{array}{l}\text { Reporting and } \\
\text { interpretation }\end{array}$ \\
\hline $\begin{array}{l}\text { Check ambient conditions luse a } \\
\text { reliable barometer and } \\
\text { thermometer) } \\
\text { Ensure the correct system } \\
\text { settings for dead space, } \\
\text { pressure range, volume, and } \\
\text { BTPS correction } \\
\text { Accurate calibration for volume } \\
\text { and pressure } \\
\text { Check volume accuracy } \pm 75 \mathrm{~mL} \\
0-90 \% \text { response time } \leqslant 150 \mathrm{~ms} \\
\text { Linearity: } \leqslant 0.5 \% \text { of full scale } \\
\text { Accuracy: } \pm 1 \% \text { of full scale } \\
\text { Adjust for lag and response time } \\
\text { QC using regular biological } \\
\text { controls } \\
\text { Quality assurance using syringe } \\
\text { or } D_{\text {Lco gas simulator }}\end{array}$ & $\begin{array}{l}\text { Interference from } 5 \% \\
\mathrm{CO}_{2} \text { or } 5 \% \text { water } \\
\text { vapour } \leqslant 10 \mathrm{ppm} \text { error } \\
\text { in } \mathrm{CO} \\
\text { Drift for } \mathrm{CO} \leqslant 10 \mathrm{ppm} \\
\text { over } 30 \mathrm{~s} \\
\text { Drift for tracer gas } \\
\leqslant 0.5 \% \text { of full scale } \\
\text { over } 30 \mathrm{~s} \\
\text { BHT } 10 \pm 2 \mathrm{~s}\end{array}$ & $\begin{array}{l}\text { Maximum time for unforced exhalation to RV is } \\
\leqslant 12 \mathrm{~s} \\
V_{\text {insp }} \text { target of } \geqslant 90 \% \text { of largest } \mathrm{VC} \text { in same lung } \\
\text { function testing session } \\
V_{\text {insp }} \geqslant 85 \% \text { of } \mathrm{VC} \text { is acceptable if } V_{\mathrm{A}} \text { is within } 200 \mathrm{~mL} \\
\text { or } 5 \% \text { of highest } V_{\mathrm{A}} \text { from acceptable } D_{\mathrm{Lco}} \text { trial } \\
V_{\text {insp }} \text { must be }<4 \mathrm{~s} \text {, longer } V_{\text {insp }} \text { must be noted on } \\
\text { report } \\
\text { Exhalation post-BHT past sample collection on } \\
\text { classic systems }<4 \mathrm{~s} \\
\text { Exhalation to RV post BHT on RGA systems can be } \\
\text { up to } 12 \mathrm{~s} \\
\text { Between test wait time: } 4 \text { min, } 10 \text { min for patient } \\
\text { with severe airflow obstruction lon RGA, check } \\
\text { tracer gas concentration at end-exhalation } \leqslant 2 \% \\
\text { of the inspired concentration) } \\
\text { Must remain seated during wait time } \\
\text { Recommended to check end-exhalation } \mathrm{CO} \text { levels } \\
\text { prior to inhalation of test gas; this can be used to } \\
\text { adjust to the test for CO back-pressure and } \\
\text { calculate } \mathrm{COHb} \text {; allows compensation for water } \\
\text { vapour and } \mathrm{CO}_{2} \text { effects } \\
\text { Repeatability requirement: there must be at least } \\
\text { two acceptable manoeuvres that are within } \\
2 \mathrm{~mL} \cdot \mathrm{min}^{-1} \cdot \mathrm{mmHg}^{-1} \text { (0.67 mmol-min }{ }^{-1} \cdot \mathrm{kPa}^{-1} \text { ) of } \\
\text { each other }\end{array}$ & $\begin{array}{l}\text { Record when last } \\
\text { cigarette was smoked } \\
\text { Always use } D_{\mathrm{Lco}} \\
\text { corrected for } \mathrm{Hb} \text { and } \\
\text { COHb where } \\
\text { applicable } \\
\text { Clearly state if no recent } \\
\mathrm{Hb} \text { is available } \\
\text { Report the grading of } \\
\text { the } D_{\text {Lco manoeuvres }} \\
\text { Record altitude }\end{array}$ \\
\hline
\end{tabular}

QC: quality control; BTPS: body temperature and pressure, saturated; BHT: breath-holding time; RV: residual volume; $V_{\text {insp: }}$ inspiratory volume; VC: vital capacity; $V_{A}$ : alveolar volume; RGA: rapid gas analyser; $\mathrm{COHb}$ : carboxyhaemoglobin; $\mathrm{Hb}$ : haemoglobin. 
methodology. The linearity of gas concentration signals is of most importance in measuring $D_{\text {LCO }}$ since the ratios of the gas concentrations are considered in the classical calculations. Water vapour and carbon dioxide in exhaled gas are contributing factors in interface noise of up to 5\%; i.e. water vapour pressure $6.28 \mathrm{kPa}(47 \mathrm{mmHg})$ should contribute $<10 \mathrm{ppm}$ error in the measured carbon monoxide signal, while gas analysers should only have minimal drift in zero and gain, so that the output is stable over the test interval. Gas analyser drift must be $\leqslant 10 \mathrm{ppm}$ over $30 \mathrm{~s}$ for carbon monoxide and $\leqslant 0.5 \%$ of full scale over $30 \mathrm{~s}$ for the tracer gas.

\section{Standardisation of test performance}

A. McGowan (Ireland) and K. Sylvester (UK)

The $D_{\text {LCO }}$ technique was first standardised by Ogilvie and co-workers in 1957 [17]. A tracer gas was used to determine both the alveolar volume and the alveolar concentration of carbon monoxide at the beginning of breath holding. This method used the collection of discrete exhaled gas samples from which gas concentrations were measured using gas analysers that took several minutes to perform the measurements. The instrumentation for $D_{\mathrm{LCO}}$ measurement has advanced considerably since then, primarily through the use of RGA systems. The 2017 standard provides more detail on how the test should be performed when using real time gas analysers.

The new standards of $D_{\mathrm{LCO}}$ testing consider the impact of the following on test performance: the patient's condition for a variable vital capacity, exercise or position; inspiratory manoeuvres; breath-hold and expiratory manoeuvres; and washout and sample collection manoeuvres. Practical tips are presented in table 2. On the day of the test, patients should be instructed to refrain from smoking for the entire day (notes should be taken about the time of patient's last cigarette) and stay off supplemental oxygen at least 10 min before the test. Regarding residual volume [18], the maximum time of an unforced exhalation is $\leqslant 12 \mathrm{~s}$ to reach an optimal level residual volume for patients with severe obstruction. The inspiratory vital capacity now has a target of $>90 \%$ of the largest vital capacity in the same lung function session or an inspiratory vital capacity $>85 \%$ of the largest vital capacity is acceptable if the alveolar volume $\left(V_{\mathrm{A}}\right)$ is within $200 \mathrm{~mL}$ or $5 \%$ of the highest $V_{\mathrm{A}}$ from an acceptable $D_{\mathrm{LCO}}$ trial. The time to inspiratory vital capacity must be $<4 \mathrm{~s}$ and a longer inspiratory manoeuvre must be noted in the report. The exhalation post-breath-holding time (BHT) can be up to $12 \mathrm{~s}$ on the RGA and $<4 \mathrm{~s}$ on a classic system. The repeatability requirement for $D_{\mathrm{LCO}}$ states that there must be at least two acceptable manoeuvres that are within $2 \mathrm{~mL} \cdot \mathrm{min}^{-1} \cdot \mathrm{mmHg}^{-1}\left(0.67 \mathrm{mmol} \cdot \mathrm{min}^{-1} \cdot \mathrm{kPa}^{-1}\right)$ of each other. The between-test waiting time needs to be a minimum of $4 \mathrm{~min}$ and can be up to $10 \mathrm{~min}$ for a patient with severe airflow obstruction, with the patient remaining seated during the wait time. It is recommended to check end-exhalation carbon monoxide levels prior to inhalation of test gas. This can be used to adjust the test for carbon monoxide back-pressure and calculate carboxyhaemoglobin $(\mathrm{COHb})$. This allows compensation for water vapour and carbon dioxide effects.

\section{Reporting and interpretation of case studies B. Thompson (Australia) and I. Steenbruggen (the Netherlands)}

At this workstation, case reports of $D_{\mathrm{LCO}}$ testing using the new quality control grading for $D_{\mathrm{LCO}}$ manoeuvres were discussed. It is indicated to always use $D_{\text {LCO }}$ corrected for haemoglobin [19] and COHb where applicable, and to use uncorrected for haemoglobin when no recent haemoglobin is available and to state this clearly in the report. The goal of interpretation of real case studies was to determine if $D_{\text {LCO }}$ was above or below lower limit of normal and if it was an acceptable test to interpret using the new quality control grading system for acceptable $D_{\text {LCO }}$ results.

Take-home messages

- Calibrate volume, pressure and altitude accurately.

- Check if the system settings for dead space and drift are correct on the equipment

- Maintain and document all quality control measures with the use of a syringe or $D_{\text {Lco }}$ simulator.

- BHT needs to be between 8 and $12 \mathrm{~s}$ and inspiratory volume needs to be $>90 \%$, while keeping the patient seated between manoeuvres.

\section{Oral presentation session on "A fresh view on assessment of functional status in COPD"}

Accurate and systematic assessment of functional status is a requirement in the management of patients with COPD $[20,21]$ and presents a challenge in clinical practice. This oral presentation session provided new insights into currently used measures of functionality and exercise tolerance in individuals with stable and unstable COPD. 
People with COPD report higher levels of cognitive impairment [22] and pain [23] than matched healthy subjects. Such comorbidities have been linked with lower motor performance and falls in elderly [24, 25]; however, these associations have been poorly explored in individuals with COPD. REID et al. [26] showed that dual tasking (i.e. backwards spelling while walking at usual or fast paces) causes a larger increase in oxygenated haemoglobin at the prefrontal cortex and a larger decrease in walking velocity in individuals with COPD compared with matched healthy subjects. Such increases in prefrontal cortex neural activity may impact on the safety of ambulation in this population. Loughran et al. [27] explored the association of pain and incidence of falls in 883 individuals with COPD. Like studies in older adults [28], people with COPD and pain showed a greater predicted probability of falling and required more treatment for falls than controls. Additionally, the predicted probability of falling was progressively greater in more severe pain stages, with over a third of people suffering from both COPD and severe pain being predicted to fall over a 2-year time course.

Functional and submaximal constant work rate tests (CWRTs) have been extensively used to assess cardiorespiratory and muscular endurance in people with COPD [29, 30] but clear implications for practice are less studied. CASABURI et al. [31] reviewed the exercise duration of CWRTs (75-80\% of peak work rate at incremental exercise test) in 23 published studies involving 5853 participants with COPD. The authors found that $20 \%$ of the tests lasted $<3 \mathrm{~min}$ and shorter durations were more prevalent in participants with low peak work rate, independently of height, weight and age. Adjustment to reduce the baseline work rate in these individuals may increase the likelihood of achieving the recommended exercise durations between 3 and $8 \mathrm{~min}$ [32]. R. Casaburi finished his presentation with two key questions for future studies: what is the ideal work rate to achieve the target exercise lengthening, and how should the cut-off be established? Regarding muscular endurance, BERGQVist et al. [33] explored the extent to which dynamic and static muscle endurance are similarly affected in COPD. In 30 people with COPD and 30 healthy matched subjects, they found that dynamic quadriceps endurance was significantly decreased in people with COPD but no differences were found regarding static muscle endurance. As A. Nyberg elicited during this presentation, these results should motivate health professionals to shift their focus of intervention from static to dynamic muscle endurance by introducing exercise modalities particularly designed to this end in daily practice.

The increasing demand to make exercise and pulmonary rehabilitation interventions accessible for different populations and settings [34] enforces a need for more simple, quick and universally applicable tests. Oliveira et al. [35] explored the physiological responses of the 1-min sit-to-stand (STS) test and the 6-min walk test (6MWT), aiming to establish whether these tests could be used interchangeably in patients with COPD and interstitial lung diseases [36]. Strong correlations were found between Borg dyspnoea scores at the end of both tests. In addition, the number of repetitions in the 1-min STS test was able to predict $50-63 \%$ of the variability in the $6 \mathrm{MWT}$. No correlations were found between tests regarding physiologic parameters (i.e. blood pressure, heart rate and peripheral oxygen saturation). Although the 6MWT and 1-min STS test cannot be used interchangeably, the 1-min STS may still provide important information about patients' functional status in space-limited settings.

Two studies explored the application of functional tests during acute exacerbations of COPD. MACHADO et al. [37] showed that a cut-off of 13.7 repetitions in the five-repetition STS test could differentiate between patients who were admitted to the hospital $(n=15)$ and those who were sent to be treated in the community $(n=32)$ with a sensitivity of $75 \%$ and specificity of $53 \%$. A. Machado further highlighted the relevance of these results for admission purposes by showing that no other parameter (i.e. age, sex, lung function, body mass or quadriceps muscle strength) was able to differentiate between these populations. The discussion among the delegates in the session concluded that future studies could explore the usefulness of the five-repetition STS test when combined with the measures proposed by the Global Initiative for Chronic Obstructive Lung Disease (GOLD) [18] (e.g. work of breathing, impaired gas exchange and comorbidities) to decide on patients' hospital admission or discharge. OsaDNIK et al. [38] evaluated frailty as a prognostic factor for 90-day readmission in patients hospitalised for an acute exacerbation of COPD. Frailty was associated with a 4.5-fold risk of readmission; and those readmitted took longer to perform the five-repetition STS test at the first admission, and improved less in the five-repetition STS test, 6MWT and quadriceps muscle strength from first admission to 1 month post-discharge. These results call attention to the need to target frail people with acute exacerbations of COPD for comprehensive interventions like pulmonary rehabilitation to improve their functional status and possibly prevent readmissions.

Although functional status is often related to the performance in physical tasks, it may also be assessed using patient-reported outcome measures, and indeed their use has been advocated to provide a more patient-centred service [39]. JANSSENS et al. [40] developed and evaluated the psychometric properties of a comprehensive dyspnoea tool composed of four numeric rating scales in 379 participants with COPD. The 
scale showed adequate internal consistency, test-retest reliability and content validity against the COPD Assessment Test and the St George's Respiratory Questionnaire, and responsiveness to pulmonary rehabilitation. A minimal clinically important difference (MCID) of 4 points was also established.

Finally, all studies emphasised the relevant information that can be retrieved from simple and easily implemented functional and exercise tests, and that may influence health professionals' course of practice.

Take-home messages

- Functional status in COPD can be highly affected by pain, frailty and dual tasking.

- Field tests (i.e. 6MWT, 1-min STS and five-repetition STS), laboratory tests (CWRT and computerised dynamometryl and patient-reported outcome measures can help identify different components of functional status in patients with COPD.

\section{Oral presentation on "Insights into rehabilitation and physical activity of patients with respiratory diseases"}

Improving pulmonary rehabilitation and physical activity uptake and outcomes are currently hot topics in research and priorities in clinical practice. This oral presentation session included a sample of the highest quality research currently being conducted in rehabilitation (three studies) and physical activity (four studies) in people with stable and unstable COPD and in individuals with lung cancer.

Outcomes of inspiratory muscle training may be affected by the device used and the assessment techniques [41]. VAN Hollebeke et al. [42] showed that training with both mechanical threshold loading and tapered flow resistive loading devices increases maximal inspiratory pressure $\left(P_{\text {Imax }}\right)$ at different lung volumes (i.e. residual volume, functional residual capacity and functional residual capacity-total lung capacity) in healthy individuals. However, only the tapered flow resistive loading increased the inspiratory peak flow on functional residual capacity and functional residual capacity-total lung capacity against a resistance of $0 \%, 20 \%, 30 \%$ and $50 \%$ of the baseline $P_{\operatorname{Imax}}$, thus improving the velocity of shortening and muscle power.

Resistance training is a core component of pulmonary rehabilitation [18] but the optimal intensity for training is yet to be established [43]. BARUSSO-GrüNINGER et al. [44] compared low load/high repetition (LL/HR) (30\% of the patient's one-repetition maximum (1RM) for three sets of 15 repetitions) versus high load/low repetition (HL/LR) (60\% $1 \mathrm{RM}$ for three sets of eight repetitions) resistance training in a randomised controlled trial enrolling 27 people with COPD. Improvements in dyspnoea during activities of daily living, the London Chest Activity of Daily Living scale (physical and total score), 6MWT and shoulder flexor strength were observed in both groups. However, the symptom subscore of the St George's Respiratory Questionnaire improved significantly more in the LL/HR than in the HL/LR group.

In recent years, increasing exercise capacity and physical activity have gained importance as treatment goals in people with lung cancer [45]. One systematic review and a randomised controlled trial that were presented aimed to improve knowledge on this field. The findings of the updated Cochrane review on the effects of exercise training following lung resection for non-small cell lung cancer were explained by CAVAlHeri et al. [46]. Moderate to high certainty evidence suggests that exercise capacity and peripheral muscle strength improve with exercise training compared to control conditions, with the difference in the 6MWT (mean difference $57 \mathrm{~m}, 95 \%$ CI 34-80 m) being greater than the MCID in this population (from 22 to $42 \mathrm{~m}$ ) [46]. An improvement in the physical component of general health-related quality of life (HRQoL) and less dyspnoea were also observed in the exercise training group; however, both outcomes present low to very low certainty evidence. These findings emphasise the need to refer patients following lung resection to exercise training programmes. EDBRooke et al. [47] explored the effects of 8 weeks of home-based rehabilitation compared with usual care in 92 participants with inoperable lung cancer. At baseline, they found that $\sim 70 \%$ of participants did not meet the international physical activity guidelines [48], with low physical activity being significantly associated with the presence of cachexia. No significant differences were observed between the home-based rehabilitation and control groups at 9 weeks and 6 months with regard to changes in the number of steps per day and step bouts per day ( $\geqslant 10 \mathrm{~min})$; however, recruitment is still ongoing.

People with COPD experience a physical activity decline over time of $\sim 450$ steps per year, which impacts negatively on HRQoL and lung function [49]. KORENy et al. [50] identified three physical activity trajectory patterns (inactive, active decliners and active improvers) using a cohort of 293 patients with COPD. People with low exercise capacity and worse dyspnoea presented high probability of being inactive at baseline and experiencing a natural decline in physical activity (508 steps per year) over the 12-month follow-up period (inactive trajectory, $\mathrm{n}=173$ ). However, no determinants at baseline were identified for active decliners 
(those presenting appropriate levels of physical activity at baseline and a spontaneous decrease in physical activity after 12 months, $\mathrm{n}=69$ ) and active improvers (those walking 7000 steps per day at baseline and increasing physical activity after 12 months, $n=51$ ). Physical activity interventions should thus be considered in all patients with COPD because it is currently not possible to predict who will have an active decline or active improve trajectory over time.

Although exacerbations were not identified as a determinant of physical activity trajectory in the study by KoRENy et al. [50], previous studies have shown that exacerbations have a negative impact on physical activity [51]. GONZALEz et al. [52], explored the barriers and enablers associated with physical activity 1 week after hospital discharge for a severe acute exacerbation of COPD. The most frequently reported barriers were linked to physical and psychological conditions (i.e. incomplete recovery, dyspnoea, lower mood for this activity and fear of worsening), disliking the activity and suboptimal environmental conditions. However, only environmental factors were significantly related to fewer steps per day after discharge $(p=0.01)$. Conversely, daily routine $(p=0.05)$ and hobbies $(p=0.008)$ were the enablers significantly related with high number of steps per day. These findings should be considered when interventions are designed to promote physical activity after exacerbations in people with COPD.

Disease-specific fears are important factors to address when referring people to pulmonary rehabilitation $[19,53]$ or physical activity interventions. In 34 people with COPD, REIJNDERs et al. [54] observed that greater dyspnoea-related fear is moderately correlated with low physical activity (steps per day) and people who reduced their fear of dyspnoea after a pulmonary rehabilitation programme achieved greater improvements in physical activity. The authors also found that the level of attention to respiratory sensations (assessed by cerebral activity during a short inspiratory occluded manoeuvre) had a positive correlation with dyspnoea-related fear $(\mathrm{r}=0.47)$ and a negative correlation with the level of physical activity $(\mathrm{r}=-0.40)$. However, this outcome measure only seemed to change after pulmonary rehabilitation in a subgroup of patients with COPD; thus, further research is needed to confirm this finding, and to identify whether these patients are more likely to respond to exercise training and physical activity interventions.

Take-home messages

- Outcomes of inspiratory and peripheral muscle training are affected by the equipment used (i.e. mechanical threshold loading versus tapered flow resistive loading) and type of training implemented (HL/LR versus LL/HR).

- Exercise training improves exercise capacity and peripheral muscle strength in people following lung resection for non-small cell lung cancer.

- Physical activity interventions should be considered in all patients with COPD because it is currently not possible to predict the physical activity trajectory (inactive, active decliners or active improvers) over time.

- Daily routine and hobbies are enablers of physical activity in people with COPD after a hospital admission; however, geographical factors may act as a barriers to increase physical activity.

\section{Symposium on "The added value of allied healthcare professionals in integrated respiratory care"}

People with chronic respiratory conditions present not only deterioration of lung function and functional capacity, but also changes in psychosocial abilities and lifestyle, which negatively impact the prognosis of the disease $[20,55]$. Bill Mansell, an individual with sarcoidosis, opened this symposium by emphasising the importance of having access to a coordinated multidisciplinary and integrated care programme to achieve the greatest possible benefits in those with chronic respiratory diseases. According to B. Mansell's experience, contact with AHPs marked a turning point in his life, and was essential to improving his self-management and symptom control. B. Mansell's testimonial on the disease challenges and the supportive role of AHPs set the scene for an eye-opening symposium about the value of AHPs.

Integrated care programmes have already been demonstrated to reduce the number of readmissions, improve HRQoL and reduce health care utilisation [56-58]. As Eileen Collins showed in her talk entitled "Nurses: the spider in the web of integrated respiratory care?", most of these programmes are led by specialised nurses because their generalist background gives them a global view of the patient. Moreover, nurses are seen by patients as easily approachable and trustworthy, which are key aspects to ensure the success of these programmes. Consequently, nurses are a key element in optimising patient management in integrated care programmes.

The talk entitled "Occupation therapy: making daily life easier" by Louise Sewell made us aware of the importance of occupational therapists to increase patients' performance beyond their functional capacity, as only this training will allow them to achieve maximum performance during daily life activities [36]. Occupational therapists are responsible for advising patients on how to optimise their daily activities by 
facilitating energy conservation and planning environmental adaptions. Consequently, these healthcare professionals play a great part in improving some of the skills that matter the most to patients.

Corrine Handson shared the recent guidelines on nutritional care for individuals with COPD promoted by the Academy of Nutrition and Dietetics in the USA in her talk entitled "Dietary counselling: the fatter the better?". Body composition is associated with mortality, with overweight classification presenting the lowest risk of mortality in patients with COPD. In addition, higher body mass index is associated with greater lung function (percent predicted forced expiratory volume in $1 \mathrm{~s}$ ) and with slow lung function decline in people with COPD. Nevertheless, these findings should be carefully interpreted as the studies included did not consider the influence of possible confounders. To ensure a successful nutritional intervention, expert dieticians recommend awakening patients' motivation to improve their nutritional condition and actively involving patients in the development of treatment plans. Additional information about the guidelines can be found at www.andeal.org.

Andreas Von Leupoldt clarified that psychological comorbidities have a negative impact on the prognosis of COPD [55] in his talk entitled "Psychological counselling: train the brain". However, they are often underdiagnosed [59] and poorly treated [60]. Recently, it was observed that greater disease-specific fears (i.e. fear of dyspnoea, physical activity and disease progression) are related to lower exercise capacity, poor HRQoL and worse dyspnoea in people with COPD [53]. The evidence to recommend psychopharmacological treatment is insufficient in COPD and as these medications are related to side-effects and increased risk of mortality [61], other options should be considered. Cognitive behaviour therapy is a potential option to improve anxiety and depression in COPD, although its role in other outcomes (i.e. HRQoL and exacerbations) is still unclear [61, 62]. Pulmonary rehabilitation is also promising, as it not only improves general and specific psychological comorbidities but may also change how the brain processes respiratory sensations [54]; however, further research is needed to confirm this finding. Von Leupoldt concluded his talk by encouraging the audience to train not only people's lungs but also their brain.

Take-home messages

- Contacts with AHPs mark a turning point in patients' life, and are essential to improve self-management and symptoms control.

- Occupational therapists optimise the daily life of patients by facilitating energy conversation strategies and planning environmental adaptions.

- Nurses are key elements in optimising patient management in integrated care programmes.

- Nutritional interventions are essential in the management of COPD because body composition is associated with mortality.

- Pulmonary rehabilitation improves general and specific psychological comorbidities, which impact negatively on the prognosis of COPD, and may also change how the brain processes respiratory sensations

\section{Thematic poster session on “Nursing care across the spectrum of respiratory illness"}

This thematic poster session provided an overview of state-of-the-art advances in nursing care related to respiratory conditions by focusing on three main themes: nurse-led interventions; training and development for respiratory nurses; and electronic learning (e-learning).

\section{Nurse-led interventions}

Pereira et al. [63] conducted a systematic review to identify the impact of nurse-led interventions related to self-care in COPD. After full-text reviews, only one randomised clinical trial could be included in this review [64]. The included study aimed to identify the effect of a home-based pulmonary rehabilitation programme on self-care behaviours of COPD patients in GOLD stage 2 and 3. Patients were randomised to pulmonary rehabilitation or routine care consisting of drug therapy (20 in each group) from a specialised centre in Iran. As self-care is difficult to assess due to the lack of reliable instruments [65], authors evaluated physical consequences of the lack of self-care. Thus, the intervention had a positive effect on fatigue, activities of daily living and quality of life. PereIra et al. [63] concluded that there is a need to develop robust studies assessing the impact of nurse-led interventions on the capacity for self-care of people with COPD.

Pedersen et al. [66] presented the results of a pilot study to detect early signs that predict the onset of an acute exacerbation of COPD in patients with home long-term noninvasive therapy (LT-NIV). This study used a combination of automatic recordings from LT-NIV devices as well as patients' symptoms (submitted via online app or phone calls). Their results showed that an increased use of acute inhaler 
medication was the best predictor of COPD exacerbations, followed by increased mucus and higher respiratory rate.

\section{Training and development for respiratory nurses}

The importance of continuous education in respiratory nursing care was also highlighted in this poster session. SAvocic et al. [67] described the level of knowledge on chest drainage before and after training for 417 participants in Croatia. The initial average level was 65\% (9-99\%) improving to 84\% (22-99\%) post-training. Mongodi et al. [68] presented a short theoretical training ( $3 \mathrm{~h}$ during the diploma in critical nursing) to improve the interpretation of lung sliding ultrasound images to detect the presence of a pneumothorax. After the training, a significant improvement $(p<0.001)$ was found. However, the average correct interpretations remained rather low $(37.1 \pm 15.3 \%)$, which suggests a potential change is needed in clinical practice and education reinforcement for this clinical assessment. Moreover, a qualitative research project captured an important identity breach between the current practice and the visualised future for respiratory nurses in Spain [69]. Senior respiratory nurses $(n=12)$ described current practice in three themes: technical skills, multidisciplinary alliances and self-learning. These themes were linked with continuous education, motivation and personal efforts to update knowledge and skills. In addition, participants detected challenges for their professional development. They aimed to develop a regulated framework to recognise a respiratory nursing speciality, specialised clinical academic training and the use of a standardised taxonomy for respiratory nursing care. Interestingly, these senior respiratory nurses recognised engagement and collaboration within scientific societies as important to achieve their desired specialist role in respiratory nursing. Professional networks were also presented as a potential opportunity to develop the profile of respiratory professionals. For example, the UK network SiLVaH (Specialist in Long-term Ventilation at Home) aims to support nurses and AHPs working in the community setting [70].

\section{E-learning}

Two innovative projects highlighted e-learning as an education opportunity to enhance skills and update knowledge between respiratory professionals. Ecare-COPD [71] is an online training programme integrating modules on self-management, pulmonary rehabilitation and virtual simulations for clinical scenarios in COPD. This e-learning tool was available in three levels (nursing students, general nurses and specialist nurses) with positive feedback from users in terms of usefulness, easiness and intention to use.

Similarly, a group from New Zealand [72] developed an online training programme for respiratory professionals including four modules: asthma fundamentals; asthma management; COPD management; and health-promoting practice. Participants completing these modules found this e-learning tool enjoyable, easy to complete and relevant to their practice. Additionally, qualitative data revealed six major themes to inform future development of the modules: increased confidence; increased knowledge; improved and informed practice; educate patients; educate colleagues; and culturally appropriate care.

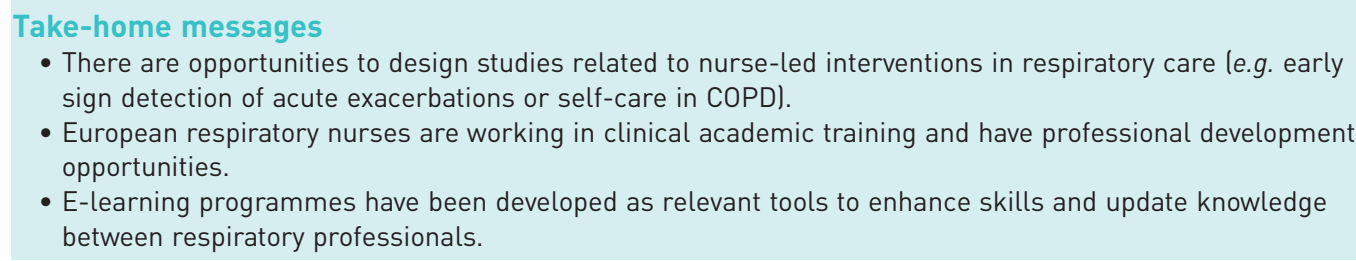

\section{Concluding remarks}

This article highlights some of the most memorable 2019 ERS International Congress sessions, and provides readers with valuable insight into some of the emerging and future areas affecting clinical practice of AHPs. The authors want to inspire the readers' enthusiasm to appreciate the value of keeping abreast of an ever-changing clinical landscape within their field of interest. With this in mind, the authors welcome everyone to join them in Vienna in 2020 for the next highly successful ERS International Congress. Auf Wiedersehen!

Conflict of interest: None declared.

Support statement: J. De Brandt is funded by the Flemish government. The Research of FWO Aspirant J. De Brandt is sponsored by FWO grant number 11B4718N. C. Burtin is funded by Limburgs Kankerfonds.

\section{References}

1 Graham BL, Steenbruggen I, Miller MR, et al. Standardization of spirometry 2019 update. An official American Thoracic Society and European Respiratory Society technical statement. Am J Respir Crit Care Med 2019; 200: e70-e88. 

statement from the Australian and New Zealand Society of Respiratory Science. Respirology 2016; 21: 1201-1209.

3 Swanney MP, Miller MR. Adopting universal lung function reference equations. Eur Respir J 2013; 42: 901-903.

4 Hall GL, Thompson BR, Stanojevic S, et al. The Global Lung Initiative 2012 reference values reflect contemporary Australasian spirometry. Respirology 2012; 17: 1150-1151.

5 Swanney MP, Ruppel G, Enright PL, et al. Using the lower limit of normal for the FEV1/FVC ratio reduces the misclassification of airway obstruction. Thorax 2008; 63: 1046-1051.

6 Miller MR, Quanjer PH, Swanney MP, et al. Interpreting lung function data using $80 \%$ predicted and fixed thresholds misclassifies more than $20 \%$ of patients. Chest $2011 ; 139$ : 52-59.

7 Swanney MP, O’Dea CA, Ingram ER, et al. Spirometry training courses: Content, delivery and assessment - a position statement from the Australian and New Zealand Society of Respiratory Science. Respirology 2017; 22: 1430-1435.

8 Swanney MP, Jensen RL, Crichton DA, et al. $\mathrm{FEV}_{6}$ is an acceptable surrogate for FVC in the spirometric diagnosis of airway obstruction and restriction. Am J Respir Crit Care Med 2000; 162: 917-919.

9 Epton MJ, Stanton JD, McGeoch GR, et al. The development of a community-based spirometry service in the Canterbury region of New Zealand: observations on new service delivery. NPJ Prim Care Respir Med 2015; 25 : 15003.

10 Miller MR, Hankinson J, Brusasco V, et al. Standardisation of spirometry. Eur Respir J 2005; 26: 319-338.

11 Graham BL, Brusasco V, Burgos F, et al. 2017 ERS/ATS standards for single-breath carbon monoxide uptake in the lung. Eur Respir J 2017; 49: 1600016.

12 Culver BH, Graham BL, Coates AL, et al. Recommendations for a standardized pulmonary function report. An official American Thoracic Society technical statement. Am J Respir Crit Care Med 2017; 196: 1463-1472.

13 Zavorsky GS, Hsia CC, Hughes JM, et al. Standardisation and application of the single-breath determination of nitric oxide uptake in the lung. Eur Respir J 2017; 49: 1600962.

14 Jensen RL. Laboratory quality control using a DLCO simulator. Eur Respir J 2005; 26: Suppl. 49 , 1149.

15 Porszasz J, Stringer W, Casaburi R. Equipment, measurements and quality control. In: Palange P, Laveneziana P, Neder JA, et al., eds. Clinical Exercise Testing (ERS Monograph). Sheffield, European Respiratory Society, 2007; pp. 108-128.

16 Krogh M. The diffusion of gases through the lungs of man. J Physiol 1915; 49: 271-300.

17 Blakemore WS, Forster RE, Morton JW, et al. A standardized breath holding technique for the clinical measurement of the diffusing capacity of the lung for carbon monoxide. J Clin Invest 1957; 36: 1-17.

18 Spruit MA, Singh SJ, Garvey C, et al. An official American Thoracic Society/European Respiratory Society statement: key concepts and advances in pulmonary rehabilitation. Am J Respir Crit Care Med 2013; 188 : e13-e64.

19 Janssens T, Van de Moortel Z, Geidl W, et al. Impact of disease-specific fears on pulmonary rehabilitation trajectories in patients with COPD. J Clin Med 2019; 8: E1460.

20 Esteban C, Garcia-Gutierrez S, Legarreta MJ, et al. One-year mortality in COPD after an exacerbation: the effect of physical activity changes during the event. COPD 2016; 13: 718-725.

21 Global Initiative for Chronic Obstructive Lung Disease. Global Strategy for Diagnosis, Management, and Prevention of Chronic Obstructive Pulmonary Disease - 2019 Report. Available from: www.goldcopd.org.

22 Oancea C, Tudorache E, Tudorache V. Neurocognitive impairment as systemic effects of COPD. In: McCarthy M, ed. COPD - an update in pathogenesis and clinical management. London, IntechOpen Limited, 2018 ; pp. 67-85.

23 van Dam van Isselt EF, Groenewegen-Sipkema KH, Spruit-van Eijk M, et al. Pain in patients with COPD: a systematic review and meta-analysis. BMJ Open 2014; 4: e005898.

24 Muir SW, Gopaul K, Montero Odasso MM. The role of cognitive impairment in fall risk among older adults: a systematic review and meta-analysis. Age Ageing 2012; 41: 299-308.

25 Stubbs B, Schofield P, Binnekade T, et al. Pain is associated with recurrent falls in community-dwelling older adults: evidence from a systematic review and meta-analysis. Pain Med 2014; 15: 1115-1128.

26 Reid WD, Kasawara KT, Hassan SA, et al. Effects of dual tasking during walking on motor and cognitive performance in COPD. Eur Respir J 2019; 54: Suppl. 63, OA3811.

27 Loughran KJ, Batterham A, Tough D, et al. The association of comorbid pain with incident falls in people with chronic obstructive pulmonary disease. Eur Respir J 2019; 54: Suppl. 63, OA3809.

28 Leveille SG, Jones RN, Kiely DK, et al. Chronic musculoskeletal pain and the occurrence of falls in an older population. JAMA 2009; 302: 2214-2221.

29 Bui KL, Nyberg A, Maltais F, et al. Functional tests in chronic obstructive pulmonary disease, part 2: measurement properties. Ann Am Thorac Soc 2017; 14: 785-794.

30 Troosters T, Casaburi R, Gosselink R, et al. Pulmonary rehabilitation in chronic obstructive pulmonary disease. Am J Respir Crit Care Med 2005; 172: 19-38.

31 Casaburi R, Hamilton A, Spruit M, et al. Predictors of low endurance time in constant work rate cycle testing in COPD. Eur Respir J 2019; 54: Suppl. 63, OA3812.

32 Puente-Maestu L, Palange P, Casaburi R, et al. Use of exercise testing in the evaluation of interventional efficacy: an official ERS statement. Eur Respir J 2016; 47: 429-460.

33 Bergqvist M, Lindahl M, Frykholm E, et al. Dynamic and static quadriceps muscle endurance in people with COPD and healthy age and gender-matched controls. Eur Respir J 2019; 54: Suppl. 63, OA3814.

34 Habib GMM, Rabinovich R, Divgi K, et al. Systematic review (protocol) of clinical effectiveness and models of care of low-resource pulmonary rehabilitation. NPJ Prim Care Respir Med 2019; 29: 10.

35 Oliveira TJM, Pinto P, Almeida V, et al. Performance of one-minute sit-to-stand test as a predictor of six-minute walk test results. Eur Respir J 2019; 54: Suppl. 63, OA3816.

36 Nakken N, Janssen DJ, van den Bogaart EH, et al. Patient versus proxy-reported problematic activities of daily life in patients with COPD. Respirology 2017; 22: 307-314.

37 Machado A, Oliveira A, Vieira M, et al. Can the five repetition sit-to-stand test discriminate inpatients and outpatients with acute exacerbations of COPD? Eur Respir J 2019; 54: Suppl. 63, OA3815.

38 Osadnik C, Kavanagh A, Macdonald M, et al. Characteristics of frail patients with acute exacerbations of COPD who experience readmissions. Eur Respir J 2019; 54: Suppl. 63, OA3813.

39 Hodson M, Andrew S, Roberts CM. Towards an understanding of PREMS and PROMS in COPD. Breathe 2013; 9: 358.

40 Janssens T, Geidl W, Carl J, et al. Reliability and validity of dyspnea numeric rating scales as a patient-reported outcome in pulmonary rehabilitation of COPD. Eur Respir J 2019; 54: Suppl. 63, OA3810. 
41 Langer D, Charususin N, Jácome C, et al. Efficacy of a novel method for inspiratory muscle training in people with chronic obstructive pulmonary disease. Phys Ther 2015; 95: 1264-1273.

42 Van Hollebeke M, Gosselink R, Langer D, et al. Lung volume and flow specificity of two inspiratory muscle training protocols. Eur Respir J 2019; 54: Suppl. 63, OA5355.

43 Nolan CM, Rochester CL, et al. Exercise training modalities for people with chronic obstructive pulmonary disease. COPD 2019; 16: 378-389.

44 Barusso-Grüninger M, Gianjoppe-Santos J, Pires Di Lorenzo VA, et al. Impact of different intensities of resistance training on health status focusing on activities of daily living in patients with COPD: randomized controlled study. Eur Respir J 2019; 54: Suppl. 63, OA5356.

45 Bade BC, Thomas DD, Scott JB, et al. Increasing physical activity and exercise in lung cancer: reviewing safety, benefits, and application. J Thorac Oncol 2015; 10: 861-871.

46 Cavalheri V, Burtin C, Formico VR, et al. Exercise training undertaken by people within 12 months of lung resection for non-small cell lung cancer. Cochrane Database Syst Rev 2019; 6: CD009955.

47 Edbrooke L, Granger C, Clark R, et al. Physical activity in inoperable lung cancer. Eur Respir J 2019; 54: Suppl. 63, OA5357.

48 World Health Organization. Global recommendations on physical activity for health. Geneva, World Health Organization, 2010.

49 Troosters T, Blondeel A, Rodrigues FM, et al. Strategies to increase physical activity in chronic respiratory diseases. Clin Chest Med 2019; 40: 397-404.

50 Koreny M, Demeyer H, Arbillaga-Etxarri A, et al. Physical activity trajectories and their determinants in COPD: a cohort study. Eur Respir J 2019; 54: Suppl. 63, OA5361.

51 Demeyer H, Costilla-Frias M, Louvaris Z, et al. Both moderate and severe exacerbations accelerate physical activity decline in COPD patients. Eur Respir J 2018; 51: 1702110.

52 Gonzalez BV, Rodriguez E, Gomez A, et al. Barriers to and enablers of physical activity following a hospitalisation for COPD exacerbation. Eur Respir J 2019; 54: Suppl. 63, OA5360.

53 Reijnders T, Schuler M, Wittmann M, et al. The impact of disease-specific fears on outcome measures of pulmonary rehabilitation in patients with COPD. Respir Med 2019; 146: 87-95.

54 Reijnders T, Loeckx M, Machado Rodrigues F, et al. The impact of disease-specific fear on the neural processing of respiratory sensations and physical activity in COPD. Eur Respir J 2019; 54: Suppl. 63, OA5359.

55 Atlantis E, Fahey P, Cochrane B, et al. Bidirectional associations between clinically relevant depression or anxiety and COPD: a systematic review and meta-analysis. Chest 2013; 144: 766-777.

56 Ferrone M, Masciantonio MG, Malus N, et al. The impact of integrated disease management in high-risk COPD patients in primary care. NPJ Prim Care Respir Med 2019; 29: 8 .

57 Casas A, Troosters T, Garcia-Aymerich J, et al. Integrated care prevents hospitalisations for exacerbations in COPD patients. Eur Respir J 2006; 28: 123-130.

58 Garcia-Aymerich J, Hernandez C, Alonso A, et al. Effects of an integrated care intervention on risk factors of COPD readmission. Respir Med 2007; 101: 1462-1469.

59 Kunik ME, Roundy K, Veazey C, et al. Surprisingly high prevalence of anxiety and depression in chronic breathing disorders. Chest 2005; 127: 1205-1211.

60 Yohannes AM, Kaplan A, Hanania NA. Anxiety and depression in chronic obstructive pulmonary disease: recognition and management. Cleve Clin J Med 2018; 85: 2 Suppl. 1, S11-SS8.

61 Pollok J, van Agteren JE, Esterman AJ, et al. Psychological therapies for the treatment of depression in chronic obstructive pulmonary disease. Cochrane Database Syst Rev 2019; 3: CD012347.

62 Usmani ZA, Carson KV, Heslop K, et al. Psychological therapies for the treatment of anxiety disorders in chronic obstructive pulmonary disease. Cochrane Database Syst Rev 2017; 3: CD010673.

63 Pereira M, Moreira F, Machado P, et al. Impact of a nurse-led intervention on the capacity for self-care of the person with chronic obstructive pulmonary disease - systematic review of literature. Eur Respir J 2019; 54: Suppl. 63, PA1278.

64 Mohammadi F, Jowkar Z, Reza Khankeh H, et al. Effect of home-based nursing pulmonary rehabilitation on patients with chronic obstructive pulmonary disease: a randomised clinical trial. Br J Community Nurs 2013; 18 398-403.

65 Clari M, Matarese M, Alvaro R, et al. Measurement properties of instruments evaluating self-care and related concepts in people with chronic obstructive pulmonary disease: a systematic review. Heart Lung 2016; 45: $441-448$

66 Pedersen BN, Nielsen KH, Bøgesvang G, et al. Is it possible to find a predictor for detecting early signs of an COPD-exacerbation with LT-NIVpatients? Eur Respir J 2019; 54: Suppl. 63, PA1268.

67 Savovic A, Turina A, Novoselec S, et al. Chest drainage in clinical practice - how much do we think we know? Eur Respir J 2019; 54: Suppl. 63, PA1267.

68 Mongodi S, Bonaiti S, Santangelo E, et al. Lung sliding detection by nurses: impact of a short focused theoretica training. Eur Respir J 2019; 54: Suppl. 63, PA1274.

69 Arranz-Alonso S, Parra-Cordero S. A qualitative hermeneutic phenomenological research among respiratory nurses (Rsn) in Spain to understand the lived experience of their profession. Eur Respir J 2019; 54: Suppl. 63, PA1261.

70 Armstrong A. A home ventilation nursing and allied health professional network. Eur Respir J 2019; 54: Suppl. 63, PA1274.

71 Padilha M, Ribeiro A, Ramos J, et al. Innovation in nursing education - ECare-COPD. Self-management promotion in people with COPD. Eur Respir J 2019; 54: Suppl. 63, PA1277.

72 Demetriou T, Asbury E, Orsborn G. Asthma and chronic obstructive pulmonary disease training in an online environment: a new response to a growing problem. Eur Respir J 2019; 54: Suppl. 63, PA1275. 